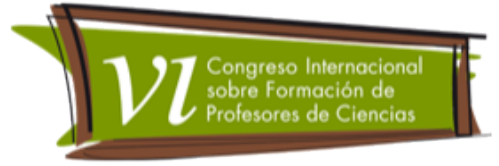

\title{
Orientaciones Para La Enseñanza De Las Ciencias Desde La Diversidad Cultural: Aspectos Relevantes De Investigación En Comunidades Culturalmente Diferenciadas
}

Melo Nádenka', Molina Adela²

Categoría 2. Trabajos De Investigación En Proceso O Concluidos

\section{Resumen}

Este trabajo explora la Enseñanza de las ciencias (EC), formación de profesores y diversidad cultural, con el objeto de identificar áreas prospectivas de investigación. A partir de la pregunta ipropician las concepciones de los profesores la enseñanza de las ciencias, en aulas con estudiantes de diversas culturas? y empleando el Mapeamiento Informacional Bibliográfico se analizaron 247 comunicaciones del Tercer Congreso Educył sobre Formación de Profesores en ciencias, el 9 Congreso Internacional de Investigación en Didáctica de las Ciencias. Se establecieron las categorías de análisis y se determinó que las cinco tendencias con mayor porcentaje se refieren a Formación inicial y permanente de profesores, Formación de profesores en ciencia y tecnología, Educación científica, Conocimiento de profesores y alumnos y Diversidad cultural. Finalmente, se identificaron áreas prospectivas de investigación y se concluye que estas orientaciones son promisorias para direccionar los estudios en EC.

\section{Palabras Clave}

Formación de profesores, diversidad cultural, Enseñanza de las ciencias

\section{Desarrollo}

Esta comunicación presenta la investigación documental sobre la Enseñanza de las Ciencias (EC) y la formación de profesores, haciendo énfasis en los principales aportes teóricos de los trabajos revisados, lo que ofrece elementos para delimitar acciones prospectivas de estudios en el área, especialmente en comunidades culturalmente diferenciadas. En primer lugar, se presenta el objetivo de la investigación, el marco teórico en torno a EC, concepciones de los profesores y

1 Universidad Distrital Estudiante DIE nbmelob@udistrital.edu.co

2 Universidad Distrital Profesora DIE Universidad Distrital 
Revista Tecné, Episteme y Didaxis: TED. Año 2014, Número Extraordinario. ISSN Impreso: 0121-3814, ISSN web: 2323-0126

Memorias, Sexto Congreso Internacional sobre Formación de Profesores de Ciencias. 08 al 10 de octubre de 2014, Bogotá

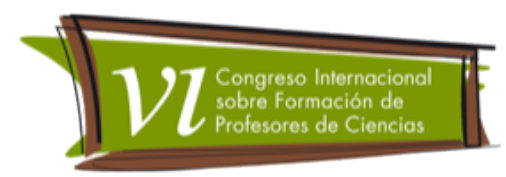

estudios de aula. Luego se presenta la pregunta alrededor de la cual se desarrolló la investigación y se discute la metodología. En la tercera sección se presentan los resultados, la discusión y las conclusiones.

El propósito de esta investigación documental es establecer relaciones entre las concepciones de los profesores y los estudios de aula en comunidades heterogéneas e identificar aspectos para investigaciones futuras en EC.

En primer lugar es necesario revisar algunos aspectos de la EC, las concepciones de los profesores y los estudios de aula:

Las diferentes aproximaciones de la EC revisadas y analizadas por El Hani \& Mortimer, 2007 incluyen el multiculturalismo, universalismo, pluralismo epistemológico y la pluralidad de razones, donde se discute el papel de la ciencia, incluido el concepto de ciencia moderna occidental y su relación con formas diferentes de conocimiento(El-Hani \& Mortimer, 2007). Dado que los profesores son los llamados a poner en marcha los currículos, sus concepciones son importantes frente a la EC; en ese sentido, desde mediados del siglo XX se ha identificado el deseo de realizar cambios en la escuela para favorecer la EC (Russell \& Martin, 2008) de forma que responda ante los nuevos retos del mundo globalizado, como la diversidad de estudiantes que llegan a las aulas, bien sea por fenómenos de migraciones o por desplazamientos forzados, entre otras razones. En así como, la formación de profesores no es ajena a esas nuevas realidades y la academia debe reflexionar sobre el quehacer de sus profesores y los profesores en formación para que estos puedan poner en práctica los avances en sus prácticas educativas.

Considerando la formación de profesores, Pozo, 1999 planteó la necesidad de revisar las concepciones de los profesores (Pozo, 1999) quienes son pilares fundamentales del cambio conceptual. Según Murphy 2012, los profesores median en el aprendizaje de sus estudiantes, ya que emplean las influencias sociales y culturales como herramientas educativas adecuadas (Murphy, 2012) en su ejercicio docente. Molina, 2012 plantea cómo en la formación de profesores se debe considerar sus concepciones, de forma tal que puedan reconocer la diversidad cultural como una potencialidad y no como una limitación en la EC (Molina, 2012).

De otro lado, el aula es el escenario donde se dan los encuentros entre los conocimientos entre estudiantes y profesores (Candela, 1999) convirtiendo la ejecución de la práctica docente en una dinámica continua, de forma tal que 
Revista Tecné, Episteme y Didaxis: TED. Año 2014, Número Extraordinario. ISSN Impreso: 0121-3814, ISSN web: 2323-0126

Memorias, Sexto Congreso Internacional sobre Formación de Profesores de Ciencias. 08 al 10 de octubre de 2014, Bogotá

no debe existir fraccionamiento entre la didáctica de las ciencias, las tareas de difusión y las prácticas de aula (Oliva, 2005). Molina y Utges, 2011 explican como en el aula se pueden integrar los conocimientos tradicionales y los conocimientos de la ciencia empleando actividades adecuadas, lo que repercute en una adecuada EC (Molina \& Utges, 2011).

\section{Metodología}

El estudio fue de tipo documental, descriptivo, a partir de la pregunta de investigación żpropician las concepciones de los profesores la enseñanza de las ciencias, en aulas con estudiantes de diversas culturas?

Sobre las fuentes de investigación, se consultaron los documentos online de las Memorias del Tercer Congreso Educyt-Formación de Profesores en ciencias (Pasto-Colombia, 2012), las memorias del 9 Congreso Internacional de Investigación en Didáctica de las Ciencias (Girona-España, 2013); como palabras claves se definieron: formación de profesores, diversidad y contexto cultural; se consideraron las versiones electrónicas en formato portable pdf.

Las categorías se establecieron como: Formación inicial y permanente del profesorado; Formación de profesores en ciencia y tecnología; Educación científica y diversidad; Diversidad cultural, multiculturalismo, etno-educación e interculturalidad y Conocimiento del profesor, del alumno y sus interacciones. Con base en lo anterior, se organizó una tabla conteniendo los siguientes datos de los documentos: referencia, año, publicación, autor, título, resumen y contenido de interés (Pinhão \& Martins, 2011) (Molina et al., 2012). La presentación de los datos se realizó en tablas para facilitar su análisis y discusión.

\section{Resultados y Discusión}

A partir de las memorias del tercer congreso Educyt, se identificaron 31 trabajos correspondiente a formación de profesores; 17 trabajos sobre conocimiento del profesor, del alumno y sus interacciones; 12 trabajos sobre diversidad cultural, multiculturalismo, etno-educación e interculturalidad. En las memorias del 9 Congreso Internacional de Investigación en Didáctica de las Ciencias, se encontró lo siguiente: sobre el tema de formación inicial y permanente del profesorado, se encontraron 167 comunicaciones; Educación científica en contexto 7 trabajos, y sobre Educación científica y cultural, 20 trabajos. Los anteriores resultados fueron sistematizados en una hoja de cálculo del programa Excel 2011 como se muestra en la Tabla 1. 
Revista Tecné, Episteme y Didaxis: TED. Año 2014, Número Extraordinario. ISSN Impreso: 0121-3814, ISSN web: 2323-0126

Memorias, Sexto Congreso Internacional sobre Formación de Profesores de Ciencias. 08 al 10 de octubre de 2014, Bogotá

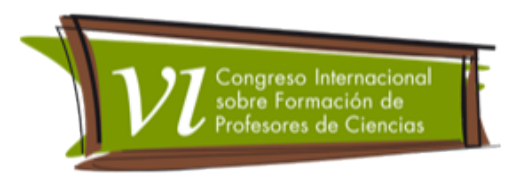

Tabla 1. Categorías identificadas a partir de la literatura

\begin{tabular}{|c|c|c|c|}
\hline Categoría identificada & $\begin{array}{l}\text { Numero de } \\
\text { publicaciones }\end{array}$ & Año & $\begin{array}{l}\text { Porcentaje de } \\
\text { artículos (\%) }\end{array}$ \\
\hline 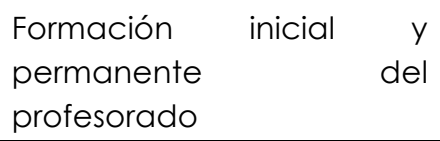 & 167 & 2013 & 67,6 \\
\hline $\begin{array}{l}\text { Formación de profesores } \\
\text { en ciencia y tecnología }\end{array}$ & 31 & 2012 & 12,6 \\
\hline $\begin{array}{l}\text { Educación científica y } \\
\text { diversidad }\end{array}$ & 20 & 2013 & 8,1 \\
\hline $\begin{array}{l}\text { El conocimiento del } \\
\text { profesor, el conocimiento } \\
\text { del alumno y sus } \\
\text { interacciones }\end{array}$ & 17 & 2012 & 6,9 \\
\hline $\begin{array}{lr}\text { Diversidad } & \text { cultural, } \\
\text { multiculturalismo, } & \text { etno- } \\
\text { educación } & \text { e } \\
\text { interculturalidad } & \\
\end{array}$ & 12 & 2012 & 4,9 \\
\hline Total & 247 & & $100 \%$ \\
\hline
\end{tabular}

De lo anterior, se puede decir que las categorías Formación inicial y permanente de los profesores con un $67.6 \%$ de las comunicaciones y la formación de profesores en ciencia y tecnología con un $12.6 \%$, siguen siendo temas prioritarios de investigación; dan cuenta de ello, la existencia y número de trabajos publicados, que resaltan la importancia de la formación de profesores, esto coincide con lo expuesto por Oliva, 2005 quien propende por la reducción de la brecha entre la formación de profesores y las investigaciones al respecto. Desde el tránsito de los profesores en formación por las facultades donde se forman y durante su ejercicio profesional, son los llamados a propiciar la puesta en contacto de las ideas y actitudes de los estudiantes con los conocimientos que se deben adquirir (Cochran, King, \& DeRuiter, 1991; Mosquera, 2013; Oliva, 2005). Para Giné et al 2009 es urgente revisar los procesos de formación permanente del profesorado para dotarlo de las estrategias necesarias que les permita desempeñar su trabajo en forma idónea (Giné, Martí, Mentado, \& Prats, 2009). 
Revista Tecné, Episteme y Didaxis: TED. Año 2014, Número Extraordinario. ISSN Impreso: 0121-3814, ISSN web: 2323-0126

Memorias, Sexto Congreso Internacional sobre Formación de Profesores de Ciencias. 08 al 10 de octubre de 2014, Bogotá

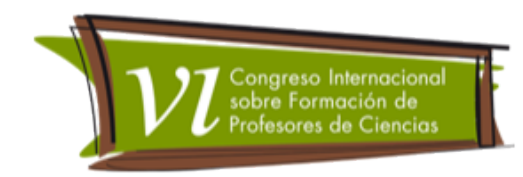

En tercer se encuentra la categoría, educación científica con un $8.1 \%$, en este sentido, este resultado coincide con lo reportado por Lemke en 2006, cuya propuesta consiste en rediseñar la educación científica, para que de deje de estar aislada de la vida cotidiana y de respuesta a las nuevas realidades como son la contribución a la alfabetización multimedial general, a las habilidades de pensamiento crítico y a mejoras a la vida social (Lemke, 2006).

El conocimiento del profesor, el conocimiento del alumno y sus interacciones ocupó el cuarto lugar con un 6,9\% de trabajos en el área. Al ser el aula es sitio donde se llevan a cabo estas interacciones, es necesario seguir investigando en ella para llenar las lagunas o vacíos identificados, y que permitan dilucidar como emergen los saberes tradicionales y científicos en ellas (Lee, 2005; Molina \& Utges, $2011)$.

Sobre la Diversidad cultural, multiculturalismo, etno-educación e interculturalidad, representó el $4,9 \%$, lo que sugiere la relevancia de considerar el origen cultural de los estudiantes. El aula de clase tiende a ser cada vez más diversa, en cuanto a idiomas y cultura, especialmente en los contextos urbanos (Cobern \& Loving, 2000; Lee, 1999, 2005) siendo el escenario de puesta en práctica de los conocimientos, provenientes de diferentes culturas. Como menciona Lee, 1999, algunos conocimientos de los niños pueden manifestarse incompatibles con sus visiones de mundo y ocasionar diferencias significativas entre estudiantes de diferentes etnias, origen socio-económico y género (Lee, 1999). Desde la perspectiva sociocultural, las investigaciones han resultando en casos exitosos de etno-educación en comunidades indígenas y de incorporación del conocimiento tradicional a el currículo de formación de los estudiantes indígenas. Así mismo, sobre las concepciones de los profesores, Molina, 2012 registra como uno de los desafíos de la enseñanza de las ciencias el superar el etnocentrismo epistemológico ya que ellos también llevan sus creencias a lo que enseñan sobre ciencia (Mckinley \& Stewart, 2012; Molina, 2012).

Estas categorías, permiten dar respuesta a la pregunta ipropician las concepciones de los profesores la enseñanza de las ciencias, en aulas con estudiantes de diversas culturas? La respuesta al interrogante en vista de aumento de publicaciones es que, en efecto, las concepciones de los profesores influyen en la EC, ya que son ellos los llamados a extender un "puente entre el plano cognitivo con el cognoscitivo" que se ejecuta y pone en marcha en el plano práctico (Mosquera, 2013). En consonancia, cuando nos enfrentamos como profesores a aulas con estudiantes de diversos orígenes étnicos y culturales 
Revista Tecné, Episteme y Didaxis: TED. Año 2014, Número Extraordinario. ISSN Impreso: 0121-3814, ISSN web: 2323-0126

Memorias, Sexto Congreso Internacional sobre Formación de Profesores de Ciencias. 08 al 10 de octubre de 2014, Bogotá

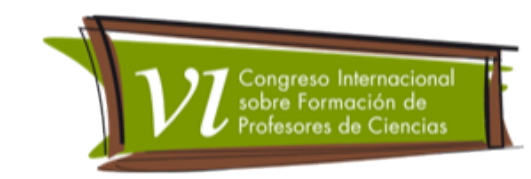

procurando el aprendizaje de ciencias, tienen más éxito los procesos en los cuales se considera el origen cultural de ellos.

\section{Reflexiones finales}

A manera de conclusión, se lograron identificar los temas que pueden orientar futuras investigaciones en el campo de EC, enfatizando las siguientes:

- Continuar con la investigación en EC de forma tal que se acerque la investigación al profesorado

- Investigar sobre el desarrollo y los logros del desempeño en las aulas de EC

- Programas de formación de profesores que permitan articular la disciplina científica con las prácticas culturales de los estudiantes

En síntesis, se reconoce que la educación de los profesores es cada vez más compleja y aprender a enseñar ciencias requiere mucha ayuda, desde todos los escenarios posibles. Es así como desde una perspectiva sociocultural, el reconocer los orígenes de estudiantes y profesores permite lograr una adecuada EC ya que al ser los profesores quienes ponen en contacto los conocimientos en el aula de clase, son los llamados a establecer los puentes para lograr un adecuado proceso de enseñanza-aprendizaje.

\section{Referencias Bibliográficas}

Candela, A. (1999). Prácticas discursivas en el aula y calidad educativa. Revista Mexicana de Investigación Educativa, 4(8), 273-298.

Cobern, W., \& Loving, C. (2000). Defining "Science" in a Multicultural Worid: Implications for Science Education. USA.

Cochran, K., King, R. A., \& DeRuiter, J. A. (1991). Pedagogical content knowledge: A tentative Model for Teacher Preparation. American Educational Research Association, 1-23.

El-Hani, C. N., \& Mortimer, E. F. (2007). Multicultural education, pragmatism, and the goals of science teaching. Culture Studies of Science Education, 2, 657702.

Giné, N., Martí, E., Mentado, T., \& Prats, M. (2009). Nuevos retos para el profesorado de secundaria: formación permanente para la atención a la 
Revista Tecné, Episteme y Didaxis: TED. Año 2014, Número Extraordinario. ISSN Impreso: 0121-3814, ISSN web: 2323-0126

Memorias, Sexto Congreso Internacional sobre Formación de Profesores de Ciencias. 08 al 10 de octubre de 2014, Bogotá

diversidad en las aulas. Magis, Revista Internacional de Investigación en Educación, 2(3), 67-88.

Lee, O. (1999). Science Knowledge, World Views, a nd Information Sources in Social and Cultural Contexts: Making Sense After a Natural Disaster. American Educational Research Journal, 36(2), 187-219.

Lee, O. (2005). Science Education and Student Diversity: Synthesis and Research Agenda. Journal of Education for Students Placed at Risk, 10(4), 433-440.

Lemke, J. L. (2006). Investigar para el futuro de la educación científica: Nuevas formas de aprender, nuevas formas de vivir. Enseñanza de las Ciencias, $24(1), 5-12$.

Mckinley, E., \& Stewart, G. (2012). Out of Place: Indigenous knowledge in the Science Curriculum (B. J. F. e. al Ed.): Springer International Handbooks of Education 24.

Molina, A. (2012). Desafíos para la formación de profesores de ciencias: aprender de la diversidad cultural. Revista Internacional del Magisterio, 57(6), 78-82.

Molina, A., Perez, M. R., Castaño, N. C., Bustos, E. H., Suarez, C. J., \& Sanchez, M. E. (2012). Mapeamiento Informacional Bibliográfico en el campo de la enseñanza de las ciencias, contexto y diversidad cultural: el caso del Journal Cultural Studies in Science Education (CSSE). Revista Educyt, V extraordinario, 197-222.

Molina, A., \& Utges, G. (2011). Diversidad cultural, concepciones de los profesores y los ámbitos de sus prácticas. Dos estudios de caso. Revista de Enseñanza de la Física, 24 (2), 7-26.

Mosquera, C. J. (2013). Syllabus Seminario Paradigmas en la Investigación en Formación de Profesores de Ciencias. Doctorado Interinstitucional en Educación. Universidad Distrital Francisco José de Caldas, 1-9.

Murphy, C. (2012). Vigotsky and Primary Science. Second International Handbook of Science Education, 1, 177-186.

Oliva, J. M. (2005). Sobre el estado actual de la revista Enseñanza de las Ciencias y algunas propuestas de futuro. Enseñanza de las Ciencias, 23(1), 123-132. 
Revista Tecné, Episteme y Didaxis: TED. Año 2014, Número

Extraordinario. ISSN Impreso: 0121-3814, ISSN web: 2323-0126

Memorias, Sexto Congreso Internacional sobre Formación de Profesores de Ciencias. 08 al 10 de octubre de 2014, Bogotá

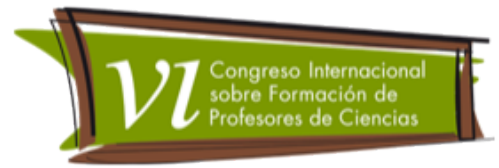

Pinhão, F., \& Martins, I. (2011). A formação de professores para o Ensino de Ciências nos Anos Iniciais: traçandoum panorama da pesquisa nacional. Atas. VIII Encontro Nacional de Pesquisa em educação em ciencias.

Pozo, J. I. (1999). Más allá del cambio conceptual: el aprendizaje de la ciencia como cambio representacional. Enseñanza de las Ciencias, 17(3), 513-520.

Russell, T., \& Martin, A. K. (2008). Learning to Teach Science Handbook of Research on Science Education (pág. 1151-1176). New York: Routledge. 